\title{
O PROCESSO DE INSTITUCIONALIZAÇÃO DA EDUCAÇÃO A DISTÂNCIA NA UFMS: TRAJETÓRIAS, RETROCESSOS E AVANÇOS
}

\author{
BATISTA, Erlinda Martins. \\ UFMS / Brasil / erlindabatista@gmail.com \\ RIEDNER, Daiani Damm Tonetto. \\ UFMS / Brasil / daiani.riedner@ufms.br
}

\section{RESUMO}

Este artigo enfoca a institucionalização da modalidade de educação a distância no contexto da Universidade Federal de Mato Grosso do Sul, tendo como base as vivências institucionais (administrativas e pedagógicas) registradas em documentos oficiais e também nas experiências das autoras. Tal processo abrange desde as iniciativas do primeiro trabalho educacional a distância realizado pelo GAECIM em meados de 1995, até a criação da SEDFOR em 2017, com vistas à ampliação da EaD na UFMS. No entanto, as ações ainda são pequenas frente aos desafios técnicos, pedagógicos, tecnológicos e de infraestrutura verificados.

Palavras-chave: Educação a distância. Institucionalização. UFMS.

\section{INTRODUÇÃO}

Este trabalho apresenta a trajetória da educação a distância - EaD no âmbito da Universidade Federal de Mato Grosso do Sul - UFMS, desde a criação do GAECIM, até o ano de 2017, quando se modificou a estrutura e organização da $\mathrm{EaD}$, passando de Coordenadoria de Educação Aberta e a Distância - CED/UFMS à uma Divisão de Educação a Distância da Secretaria Especial de Educação a Distância e Formação de Professores- DIEAD/SEDFOR. Tais mudanças constituem o processo histórico de institucionalização dessa modalidade de educação nesse contexto.

Os estudos da EaD que resultaram nesse artigo, foram realizados a partir das atividades do Grupo de Pesquisa de EaD do Centro-Oeste, - EaD - $\mathrm{CO}^{1}$, em cuja organização se destacam

\footnotetext{
${ }^{1}$ Esta pesquisa faz parte de outra maior intitulada: "Institucionalização da Educação Superior a Distância nas Universidades Federais da Região Centro-Oeste: Processos, Organização e Práticas”, apoiada pelo CNPq.
} 


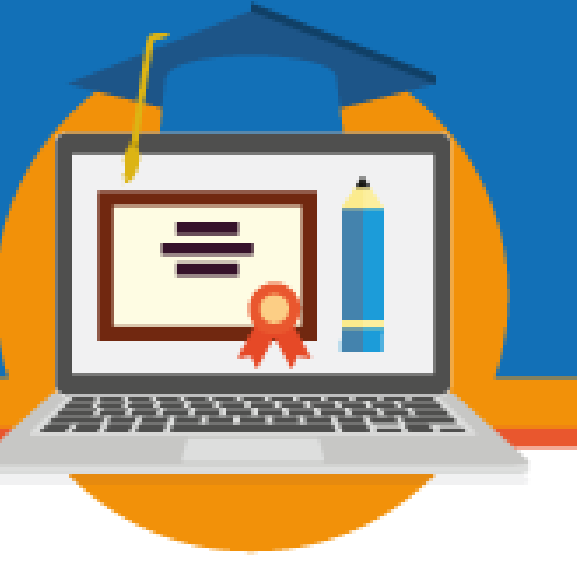

representantes de seis universidades da região Centro-Oeste, a saber: Universidade de Goiás UFG, Universidade de Brasília - UNB, Universidade Federal de Mato Grosso do Sul - UFMS, Universidade Católica Dom Bosco - UCDB, Universidade Federal da Grande Dourados UFGD e Universidade Federal de Mato Grosso - UFMT. O Grupo de Pesquisa EaD-CO, surgiu em 2015 pelas professoras da UFG e da UNB, em parceria com professoras da UFMS e UFGD, colaboradoras de programas e projetos de cursos a distância que antecedem o sistema Universidade Aberta do Brasil - UAB, e posteriormente com a adesão da UCDB e UFMT.

A motivação para esses estudos originou-se nas mudanças relacionadas ao financiamento da $\mathrm{EaD}$ no país, particularmente na institucionalização da $\mathrm{EaD}$, e nas dificuldades surgidas no final de 2014 e início de 2015, referentes à redução dos recursos para custeio dos de cursos de graduação, pós-graduação lato sensu e de extensão.

Portanto, o objetivo principal é compreender o processo de institucionalização (em curso) da EaD na UFMS, e também em universidades brasileiras que vivenciam os efeitos das mudanças. E os objetivos específicos são: discutir as condições atuais da EaD; e fomentar a continuidade dos estudos. Essas discussões justificam o presente artigo.

\section{A EDUCAÇÃO SUPERIOR A DISTÂNCIA PÚBLICA NO BRASIL}

Historicamente a Educação a Distância $(\mathrm{EaD})$ no Brasil iniciou-se com a criação da Coordenadoria Nacional de Educação a Distância no Ministério da Educação (MEC) em 1992 e, a partir de 1995, houve a implementação da Secretaria de Educação a Distância.

A Lei de Diretrizes e Bases da Educação, que foi a primeira referência sobre a EaD no Brasil estabelece, no artigo 80, que cabe ao Poder Público incentivar o desenvolvimento e a veiculação de programas de ensino a distância em todos os níveis e modalidades de ensino, e de educação continuada. (BRASIL, 1996). Assim, em 1998, o Ministério da Educação regulamentou a EaD no Brasil através dos Decretos de nº 2.494/98 (BRASIL, 1998a), 2.561/98 (BRASIL, 1998b) e Portaria $n^{\circ} 301 / 98$ (BRASIL, 1998). Posteriormente, este artigo foi regulamentado pelo Decreto n ${ }^{0}$ 5.622, no Diário Oficial da União, em 20 de dezembro de 2005, 


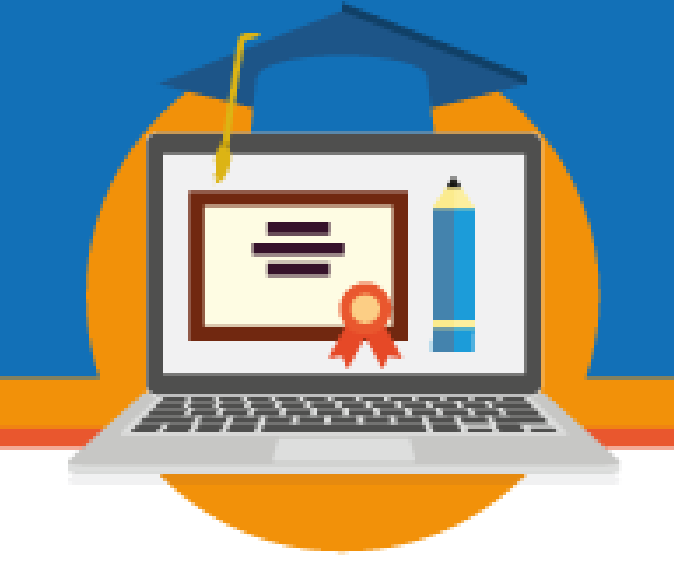

o qual revogou os decretos e portarias aprovados no período de 1998 a 2005. (GILBERTO, 2009).

Com a publicação da Portaria $n^{\circ} 4.059$, de 10 de dezembro de 2004, o MEC autorizou os cursos presenciais a oferecerem $20 \%$ de sua carga horária utilizando tecnologias da modalidade do ensino a distância, desde que as disciplinas a distância fossem previstas na estrutura curricular, com avaliações finais presenciais e atividades de tutoria.

O decreto determinou que os cursos e programas a distância tenham a mesma duração que os cursos presenciais e estabelece também a esta modalidade: a equivalência dos diplomas. Esta determinação esclarece que o curso a distância, tem a mesma carga horária do presencial, e só se diferencia pela metodologia de ensino, que é a distância e uso das tecnologias da informação e da comunicação. (GATTI, 2009).

Destarte os processos, decretos e portarias, para normatizar a EaD no Brasil, a sua consolidação só ocorreu com a Universidade Aberta do Brasil - UAB, criada pelo Decreto $\mathrm{n}^{\circ}$ 5.800, em junho de 2006. Este consolidou todas as regulamentações anteriores e deu consistência à $\mathrm{EaD}$ no país, sob gerenciamento da CAPES, com prioridade na formação de professores para a Educação Básica. O Decreto No 5.622, de 19 de dezembro de 2005, em seu Artigo $1^{\mathrm{o}}$ caracteriza a Ead como modalidade educacional na qual a mediação didáticopedagógica promove ensino e aprendizagem com o uso de tecnologias da informação e comunicação - TICs para a interação entre professores e estudantes localizados em tempos e lugares distintos.

O crescimento da EaD após a sua consolidação com a UAB, é nítido, de acordo com os dados do Censo da Educação Superior, conforme Gilberto (2009). Em 2011 a Secretaria de Educação a Distância do MEC foi extinta e criou-se a Diretoria de EaD na CAPES, que é responsável por todo gerenciamento administrativo, pedagógico e financeiro das ofertas da UAB. Atualmente, o Sistema UAB conta com 109 Instituições Públicas de Ensino Superior (IPES), ofertando 800 cursos em 771 polos. 


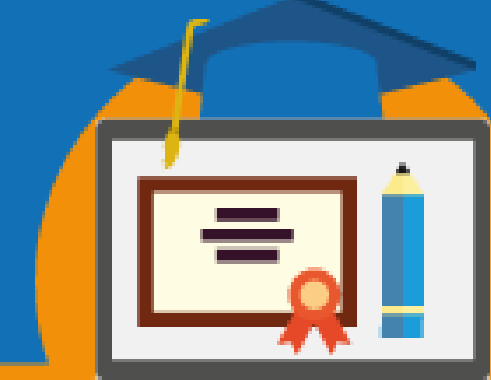

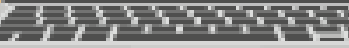

\section{A TRAJETÓRIA DA EDUCAÇÃO A DISTÂNCIA NA UFMS}

Na UFMS, a EaD iniciou-se no ano de 1991 por meio do Grupo de Apoio ao Ensino de Ciências e Matemática no $1^{\circ}$ Grau - GAECIM. O grupo era composto por professores dos departamentos de Educação, Biologia, Física, e Matemática. Entre outros propósitos, o grupo intencionava, à época, criar na UFMS um organismo interdisciplinar que oferecesse cursos de apoio aos professores da rede pública de modo a qualificá-los na modalidade a distância.

A Portaria n. 332 de 14 de agosto de 2000, editada no Boletim de Serviço da UFMS, BS 2462, anexo 01, oficializou a criação, implantação, divulgação e regimento interno da Assessoria de Educação Aberta e a Distância - AEAD na UFMS. Naquele ano os cursos a distância realizados na UFMS foram: Graduação em pedagogia na modalidade semipresencial para atender convênio com a Prefeitura de Bela Vista - MS; e Pós-graduação em nível de Especialização para profissionais da educação de Bela Vista - MS.

E 26 de setembro de 2000 por meio do Parecer 053/2000, emitido pela Comissão de Pós-graduação da Pró-reitoria de pesquisa e Pós-Graduação da UFMS, referendou-se a primeira oferta do Curso de Especialização em Orientadores Pedagógicos em Educação a Distância, cujas vagas atenderam os profissionais da educação de municípios como São Gabriel do Oeste, Rio Brilhante, Camapuã, Campo Grande, entre outros. (BATISTA, 2013).

O credenciamento da UFMS para oferta de cursos de graduação e pós-graduação na modalidade à distância ocorreu no ano de 2001, por meio da Portaria do MEC no 2.113, de 10 de setembro de 2001. Foram aprovadas as propostas do Curso de Graduação em Pedagogia Licenciatura - Habilitação em Formação de Professores para os Anos Iniciais do Ensino Fundamental e do curso de Especialização em Orientação Pedagógica em Educação a Distância. Após a implantação da graduação a distância, a UFMS concorreu ao Edital Público MEC/SEED - n⿳0 1/2004 - Seleção de propostas para apoio financeiro à Educação Superior a Distância, sendo parte de dois Consórcios de Universidade, o Pró-Formar e o Setentrional. 


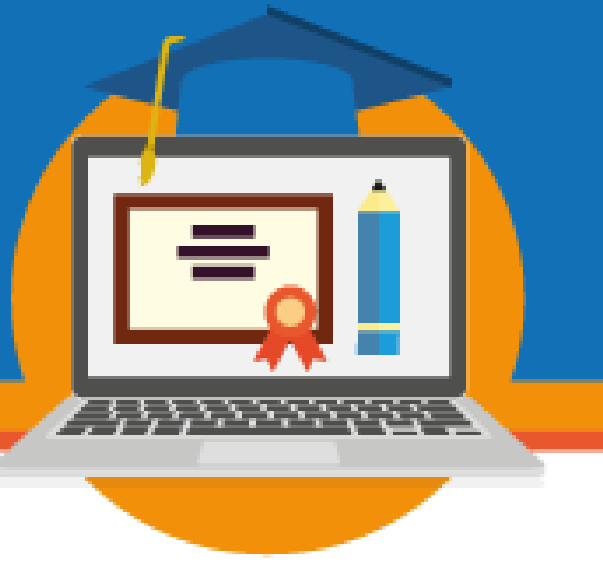

O Consórcio Pró-Formar objetivou oferecer curso de Pedagogia para Educação Infantil, sendo parceiras as instituições: Universidade Federal de Ouro Preto, Universidade Federal de Mato Grosso, Universidade do Estado de Mato Grosso, Universidade Federal de São João Del Rey, Universidade Federal de Lavras e Universidade Federal do Espírito Santo.

Pelo Consórcio Setentrional o Curso de Licenciatura em Ciências Biológicas originouse da parceria com a Universidade de Brasília, Universidade Federal de Goiás, Universidade Federal do Pará e Universidade Federal do Amazonas - ofertado na modalidade a distância, e seu Projeto Pedagógico foi elaborado e aprovado, conforme estabelecido na Resolução CNE/CP 2, de 19 de fevereiro de 2002, dentro das Diretrizes Curriculares Nacionais para os Cursos de Biologia, e dos Referenciais de Qualidade para Cursos a Distância - SEED/MEC.

A implementação da EaD na UFMS iniciou-se com a criação de polos de $\mathrm{EaD}$ nas diversas regiões do Estado de Mato Grosso do Sul e em outras unidades federativas, atendendo a demanda do MEC para a Formação de Professores e interiorização do ensino superior.

Com a política de incentivo às atividades de EaD do MEC, a UFMS, a partir de 2006, integrou-se ao sistema UAB. Naquele ano, ofertou o curso de Administração Pública (Programa Nacional de Formação em Administração Pública - PNAP). No ano anterior concorreu ao Edital $n^{0} 1 / 2005$ da Secretaria de EaD do MEC, e foi aprovada para oferecer os cursos: Pedagogia; Pedagogia (Educação Especial); Pedagogia (para Educação de Jovens e Adultos), Letras (Português/Espanhol); Matemática e Administração Pública.

Paralelamente a esses cursos a EaD/UFMS ofertou aperfeiçoamento para professores da educação básica por programas e projetos de $\mathrm{EaD}$ da SEED/MEC, financiados pelo FNDE (Fundo Nacional de Desenvolvimento da Educação) e recentemente alterado para a CAPES, como por exemplo; Curso Básico e Intermediário em Mídias na Educação, cuja primeira oferta ocorreu em 2005 para capacitar professores tutores e coordenadores para as ofertas seguintes que ocorreram em 2006, e nos anos subsequentes, até 2017, quando se oferta nesse programa, apenas em nível lato sensu o Mídias na Educação. 
Desde 2006, a primeira oferta de curso de especialização a distância registrado na PróReitoria de Pesquisa e Pós-graduação, a UFMS já formou 2.556 especialistas (na maioria professores da rede pública de ensino) de diversas áreas específicas no campo da educação.

Em cumprimento às orientações do MEC para o atendimento da demanda de formação de professores e de gestores públicos, por meio do REUNI, foram disponibilizadas vagas para o provimento de professores para atuação específica junto aos cursos de EaD da UFMS. Em 2008 publicou-se o Edital PREG n ${ }^{\circ}$ 140/2008, de 30.12.2008, que divulgava concurso para dezesseis vagas de docentes que foram lotados em 2009 na Coordenadoria de Educação Aberta e a Distância, onde permaneceram até julho de 2011. Neste ano, a UFMS passou por reestruturação, e de acordo com a Resolução COUN no ${ }^{\circ}$ 4, de 10.11.2011, a Coordenadoria de Educação Aberta e a Distância (CED), que era vinculada à Reitoria e funcionava como unidade de ensino voltou a fazer parte da Pró-Reitoria de Ensino de Graduação (PREG). As mudanças resultaram na redução do financiamento da $\mathrm{EaD}$ no período de 2011 a 2015.

Entre os anos de 2015 a 2017, os cursos de graduação tiveram seus processos seletivos suspensos devido à reestruturação da CED/UFMS, pois havia uma insegurança da gestão na viabilidade de novas ofertas, e os recursos financeiros para os cursos que estavam em andamento nesse período foram reduzidos, o que impactou as atividades presenciais nos polos. Nesse período, os docentes se apoiaram nos recursos tecnológicos, o que evidenciou a fragilidade institucional referente às tecnologias digitais disponíveis para oferta dos cursos.

A UFMS é uma universidade multicampi e possui nove unidades setoriais no interior do estado de Mato Grosso do Sul, nos municípios de Aquidauana, Chapadão do Sul, Corumbá, Coxim, Naviraí, Nova Andradina, Paranaíba, Ponta Porã e Três Lagoas. A administração da UFMS solicitou em 2018 à DED/CAPES a habilitação dos setores do interior para serem polos da UAB e assim ampliarem as ofertas de cursos a distância. Os dez Campis no interior, representam a UFMS em $25 \%$ do total de 79 municípios de MS.

Hoje, 2018, a UFMS oferece cursos nos Polos UAB de: Água Clara, Bela Vista, Bataguassu, Camapuã, Costa Rica, Miranda, Porto Murtinho, Rio Brilhante e São Gabriel do 


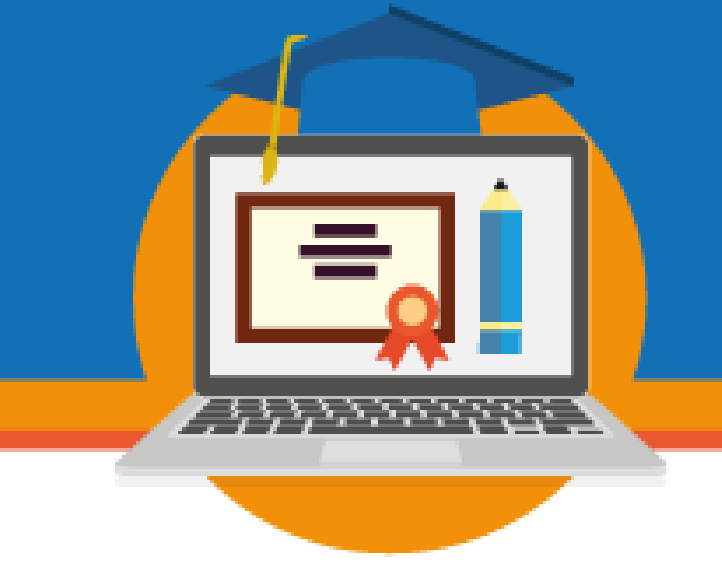

Oeste e, recentemente, estabeleceu-se o Campus de Bonito como Polo de Apoio Presencial Associado (PAP), além de um PAP na Cidade Universitária em Campo Grande - MS.

\section{A SEDFOR E O CENÁRIO DA EaD NA UFMS: NOVAS PERSPECTIVAS DE INSTITUCIONALIZAÇÃO}

Em janeiro de 2017 por meio da Resolução No 02, de 20 de janeiro de 2017 do Conselho Universitário da UFMS criou-se a Secretaria Especial de Educação a Distância e Formação de Professores - SEDFOR/RTR, cuja estrutura concentra a EaD e formação de professores, voltando integrar-se à Reitoria.

A Secretaria Especial de Educação a Distância e Formação de Professores (SEDFOR) é a unidade responsável pela articulação das políticas de ofertas de cursos e atividades mediadas por Tecnologias Digitais de cursos de graduação, pós-graduação, extensão e aperfeiçoamento na modalidade à distância, bem como pela elaboração e implementação das políticas e estratégias para a formação e capacitação de professores, condução da organização administrativa e o gerenciamento dos recursos humanos e financeiros da UAB. A SEDFOR está organizada em três divisões:

1. Divisão de Educação a Distância (DIEAD).

2. Divisão de Formação de Professores (DIFOR).

3. Divisão de Inovação de Tecnologias Educacionais e de Infraestrutura Tecnológica (DINOV).

Nessa nova organização, a DIEAD/SEDFOR, tem um papel mais técnico e de apoio pedagógico e administrativo aos cursos à distância. A DIEAD viabiliza a oferta dos cursos naquilo que diz respeito à parte específica da logística das ofertas, tais como as viagens aos polos, calendários de viagens, recursos financeiros, relacionamento com a Fundação de Apoio 


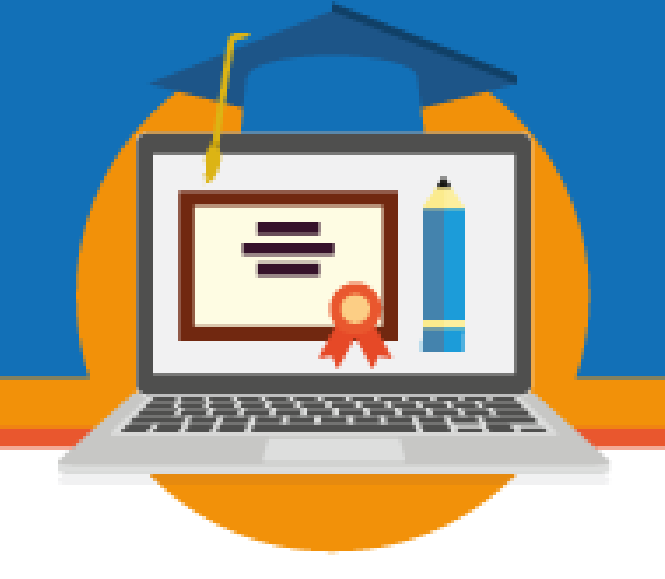

ao Ensino, à Pesquisa e à Cultura (FAPEC), que faz a gestão de parte dos recursos, atendimento às coordenações de curso e demais atividades que são demandadas pelas especificidades da EaD.

A EaD na UFMS é fomentada com recursos do Sistema UAB desde 2006. Desde então, sucessivos editais vêm proporcionando entradas na modalidade a distância para cursos de licenciatura, bacharelado e formação continuada. O último edital lançado foi o Edital 75/2014 - DED/CAPES/MEC, de dezembro de 2014. Esse edital foi reaberto em 2015, quando a UFMS enviou suas propostas.

Ainda em 2015, com o contingenciamento de recursos e um quadro geral que anunciava nova condição orçamentária, a CED/PREG foi instigada a se readequar de modo a conciliar seus quadros com recursos disponíveis. Isso demandou redução drástica de seus quadros de recursos humanos, com corte de trinta colaboradores (terceirizados) que atuavam no apoio aos cursos de graduação, extensão e lato sensu. O contingenciamento de recursos provocou uma paralização nas ações de campo dos cursos em andamento. Essa paralização, somada aos citados problemas de comunicação com os polos, impactaram no desempenho dos mesmos colocando em risco a permanência dos alunos.

Nesse cenário, a gestão optou por direcionar as novas ofertas para os polos mais próximos, melhor estruturados, em cursos com demanda comprovada e cujos quadros docentes estivessem completos. A partir desses critérios, a UFMS divulgou em setembro de 2016, o edital de ofertas para os seguintes cursos:

1. Licenciaturas em Ciências Biológicas, Letras com habilitação em Português e Espanhol, Educação Física e Pedagogia;

2. Bacharelado em Administração Pública; e

3. Pós-graduação Lato Sensu em Gestão Pública, Gestão Pública Municipal, Educação Física Escolar, Mídias na Educação, Relações étnico-raciais, gênero e diferenças no contexto do ensino de História e Cultura brasileira.

Essas ofertas tiveram procura superior ao número de vagas, em especial para os cursos de Pedagogia, Administração Pública e ofertas de lato sensu. A totalidade de vagas oferecidas 
foram 600 para cursos de graduação e 900 para cursos de lato sensu. Em agosto de 2017 foi realizado o vestibular da $\mathrm{EaD} / \mathrm{UAB}$, com 2500 inscritos para 600 vagas. Os cursos de graduação iniciaram em Agosto de 2017. E nos meses de setembro e outubro/2017 foram realizados os processos seletivos para os cursos de lato sensu, e registrou-se 2506 inscrições para 900 vagas. Os cursos de pós-graduação tiveram $100 \%$ das vagas preenchidas e iniciaram em novembro de 2017.

No ano de 2018, há 925 alunos matriculados em cursos de graduação e 900 alunos de pós-graduação, nos seguintes cursos e unidades, conforme o quadro 1 a seguir.

\section{Quadro 1 - Matrículas em cursos de graduação e pós-graduação a distância em 2018}

\begin{tabular}{|c|c|c|}
\hline Unidade & Curso & Alunos \\
\hline \multirow{6}{*}{ FAED } & Licenciatura em Pedagogia & 169 \\
\hline & Licenciatura em Educação Física & 195 \\
\hline & Pós-graduação Lato Sensu em Educação Física Escolar & 150 \\
\hline & Pós-graduação Lato Sensu em Mídias na Educação & 350 \\
\hline & $\begin{array}{l}\text { Pós-graduação Lato Sensu em Relações étnico-raciais, gênero e diferenças no contexto do Ensino } \\
\text { de História e Cultura brasileiras }\end{array}$ & 200 \\
\hline & Total da Unidade & 1064 \\
\hline \multirow{4}{*}{ ESAN } & Bacharelado em Administração Pública & 219 \\
\hline & Pós-graduação Lato Sensu em Gestão Pública & 150 \\
\hline & Pós-graduação Lato Sensu em Gestão Pública Municipal & 50 \\
\hline & Total da Unidade & 419 \\
\hline \multirow{2}{*}{ FAALC } & Licenciatura em Letras - Português/Espanhol & 122 \\
\hline & Total da Unidade & 122 \\
\hline \multirow{2}{*}{ INBIO } & Licenciatura em Ciências Biológicas & 171 \\
\hline & Total da Unidade & 171 \\
\hline \multirow{2}{*}{ INMA } & Licenciatura em Matemática & 23 \\
\hline & Total da Unidade & 23 \\
\hline \multirow{2}{*}{ FAENG } & Licenciatura em Geografia & 26 \\
\hline & Total da Unidade & 26 \\
\hline & Total de Alunos em Cursos a Distância na UFMS & 1825 \\
\hline
\end{tabular}

Organização: Batista e Riedner, (2018).

Fonte: SISCAD.

Das matrículas ativas nos cursos de graduação, 706 são de cursos de licenciatura. E na pós-graduação lato sensu, das 900 vagas, 600 são destinadas à cursos de formação continuada de professores.

No ano de 2017 a SEDFOR iniciou a implementação de ações para diminuir a evasão nos cursos a distância. A primeira foi o desenvolvimento de um sistema do Projeto Aprovado 
no EDITAL DE INOVAÇÃO N 3/2015 CAPES/UAB, intitulado "Mineração de Dados para Predição de Evasão em Ambientes de Ensino a Distância”, em desenvolvimento a partir de microdados de acesso ao ambiente virtual de aprendizagem (AVA Moodle), utilizado nos cursos de EaD da UFMS. O projeto resulta em sistema de monitoramento e alerta para gestores de $\mathrm{EaD}$, pois os resultados obtidos nessas atividades vão convergir com os módulos da ferramenta computacional da plataforma de Mineração de Dados para Predição de Evasão.

A segunda dos Assistentes à Docência, cujo perfil é de colaborador da UAB/CAPES, instituído pela PORTARIA No 183, DE 21 DE OUTUBRO DE 2016, objetivou auxiliar o coordenador de polo no acompanhamento sistemático dos alunos, nas dificuldades de permanência e uso do AVA, além de acompanhar as ações da tutoria presencial nos polos.

Com relação à gestão acadêmica, como parte das ações de institucionalização da EaD junto à UFMS, a gestão dos cursos Lato Sensu, licenciaturas e bacharelado foi repassada às respectivas unidades de ensino a partir de 2015. No entanto, a gestão dos recursos financeiros da UAB continua sendo de responsabilidade da SEDFOR, pois a Coordenação da UAB é destinada ao chefe dessa secretaria, por delegação da Reitoria.

Nos cursos de graduação, ainda existem demandas operacionais de logística das ofertas nos polos que não foram absorvidas pelas unidades setoriais responsáveis pelos cursos. Por este motivo ainda se mantém o setor acadêmico responsável pelo acompanhamento dos cursos de graduação dentro da DIEAD/SEDFOR.

Já os cursos Lato Sensu são realizados em tempo menor (18 meses) e demandam a articulação com a Pró-Reitoria de Pesquisa e Pós-graduação. Assim, a SEDFOR contrata serviços de apoio pedagógico para atender às demandas esporádicas e manter o controle e centralização da certificação dos oferecidos pela UAB e demais órgãos de fomento externo.

Dentro das ações de institucionalização, a SEDFOR iniciou em 2017 suas reuniões com todas as unidades da administração setorial na cidade universitária e em todos os campi do interior, para mostrar o trabalho que vem sendo desenvolvido, estimular os professores a participarem dos cursos e a construírem seus projetos de curso, com a possibilidade de ampliação dessas ofertas em futuros editais da CAPES. 
Além disso, várias tratativas foram iniciadas dentro da instituição a fim de colocar em pauta os cursos a distância, os alunos e docentes da $\mathrm{EaD}$, para que sejam incluídos dentro de todas as políticas e ações da UFMS, seja no ensino, na pesquisa e na extensão. Dentre essas, pode-se destacar as seguintes: 1 - Unificação do calendário acadêmico de 2018; 2 - Unificação da matrícula online para os cursos $\mathrm{EaD} ; 3$ - Revisão da resolução que regulamenta as ofertas semipresenciais e a distância nos cursos presenciais; 4 - Inclusão dos alunos da EaD nos Editais de PIBIC; e 5 - Atualização do Sistema Acadêmico (SISCAD) para melhor atender os cursos a distância;

Destaca-se ainda, a revisão da RESOLUÇÃO N 331, DE 7 DE DEZEMBRO DE 2011, do Conselho de Ensino de Graduação, que regulamenta as ofertas de disciplinas semipresenciais e a distância nos cursos de graduação presenciais da UFMS. Esse movimento é relevante, porque oportuniza aos professores experimentarem essa possibilidade de oferta, após receberem capacitação específica, e fomenta o uso de tecnologias digitais e do AVA (Moodle). A nova regulamentação aguarda a atualização do SISCAD que ainda não reconhece a carga horária das disciplinas no formato semipresencial e a distância.

Tal ação é importante, pois a referida resolução é resultado do movimento de institucionalização da EaD na UFMS que ocorreu por meio de um edital específico da CAPES (EDITAL No 015/2010/CAPES/DED), lançado em 2010. O projeto "Fomento ao uso das tecnologias de comunicação e informação nos cursos de graduação da UFMS", conhecido como "Edital 15" recebeu fomento de R\$ 1.018.783,50 (um milhão, dezoito mil reais e setecentos e oitenta e três reais e cinquenta centavos) e teve suas ações implantadas no período de julho de 2010 até Março de 2012.

A proposta institucional contou com a adesão de nove campi (81,8\% dos campi da UFMS), 63 cursos de graduação presencial (62,3\% dos cursos da UFMS), 126 professores (13\% dos professores da UFMS) e oferta de 126 disciplinas na modalidade semipresencial. Participaram do processo completo, 89 professores, ou seja, houve uma evasão de $29,3 \%$. Ao todo, 3465 acadêmicos foram matriculados em disciplinas semipresenciais. 
O projeto foi implementado em quatro subprojetos relacionados entre si. O Projeto 01 "AVA-UFMS: plataforma virtual de aprendizagem da UFMS" objetivou implantar e implementar o ambiente virtual de aprendizagem Moodle para integrar todos os cursos de graduação da UFMS, visando ampliar a organização e a desburocratização dos processos administrativos e pedagógicos, otimizando o sistema acadêmico.

Em 7 de Dezembro de 2011 o Conselho de Ensino de Graduação publicou a Resolução $\mathrm{N}^{\mathrm{o}} 331$, do Projeto 01, que regulamenta a oferta de disciplinas no formato semipresencial para os Cursos de Graduação, presenciais, da UFMS. O relatório desse projeto indica que a UFMS institucionalizou um programa para a capacitação de todos os docentes para uso das tecnologias digitais nos cursos de graduação da UFMS, porém não aconteceu. Em 2017, essa resolução foi “desengavetada", e ainda está em fase de reformulação. As ações desse projeto reformulam o Sistema Acadêmico da UFMS (SISCAD), para que considere a carga horária a distância das disciplinas semipresenciais, o que não foi implantado até 2018.

Junto com a Resolução 331, foi publicada a RESOLUÇÃO COEG N 332, DE 7 DE DEZEMBRO DE 2011, que instituía “Comissão Permanente da EaD” com objetivo de subsidiar a implantação e implementação das ações de acompanhamento, planejamento, fortalecimento e expansão do ensino a distância, dos Cursos de Graduação da UFMS.

No entanto, não há registros de ação desenvolvida pela comissão, o que indica que não houve articulação ou interesse da gestão dos setores envolvidos com as ofertas da EaD, tais como: CED/PREG, PREG e PROPP. A própria resolução 331 caiu no esquecimento, já que após os eventos do projeto, em que os professores ofereceram suas disciplinas a distância (mesmo constando no SISCAD como presenciais), as solicitações das ofertas eram restritas ao uso do AVA, às vezes sem conhecimento e/ou aprovação da referida Comissão Permanente de EaD. No ano de 2017, a DIEAD/SEDFOR suspendeu as ofertas (ainda não regularizadas no SISCAD), deixando apenas a possibilidade de os professores utilizarem o Moodle como apoio às disciplinas dos cursos presenciais.

\section{CONSIDERAÇÕES}


Historicamente, a EaD na UFMS não foi bem por quem encara essa modalidade de ensino como precarização da educação superior e do trabalho do professor. É sabido que isso não ocorre só na UFMS. Ainda hoje há quem pense que cursos a distância são aligeirados, sem consistência teórica, sem possibilidades de vivência prática da profissão.

O retrospecto apresentado nesse texto traz alguns indícios sobre o processo de (não) institucionalização da EaD na UFMS sobre o qual se debruça um pouco mais:

a) Ao que parece a gestão da $\mathrm{EaD}$ foi feita com base em indicações "políticas", pois não havia na UFMS grupo ou linha de pesquisa sobre essas questões na década de 90;

b) É perceptível que não houve uma estruturação do setor de $\mathrm{EaD}$ ao longo dos anos de financiamento da CAPES, no que concerne à capacitação de recursos humanos e desenvolvimento de tecnologias para EaD;

c) A UFMS ainda não dispõe de um setor de desenvolvimento de tecnologias e produção de materiais didáticos para $\mathrm{EaD}$, pois não há registros de uma articulação com o setor de tecnologias da UFMS, hoje denominado AGETIC. O Moodle, por exemplo, ficou 8 anos sem atualização, o que foi realizada em 2017 pela DINOV/SEDFOR;

d) Ainda há cursos que funcionam, com $60 \%$ de docentes colaboradores externos;

e) Não houve articulação entre os setores da UFMS e a CED/UFMS no sentido de pensar políticas, práticas e tecnologias para ofertas dos cursos, pois esse papel ficou restrito aos docentes vinculados à EaD e servidores técnicos-administrativos da mesma;

f) Em 2018.1 as matrículas dos cursos a distância estão sendo feitas de forma manual (em papel) nos polos, pois não houve articulação e planejamento para a matrícula online. Para 2018.2, a AGETIC está se preparando para essa demanda.

Essas percepções foram vivenciadas na prática institucional e se comprovam pelo registro das ações institucionais relativas às ofertas de cursos a distância ao longo desses anos. No ano de 2017, com a criação da SEDFOR, abriu-se perspectiva de institucionalização. Embora pareça que o fato da EaD ter se "reduzido" à DIEAD, com caráter mais técnico, não 


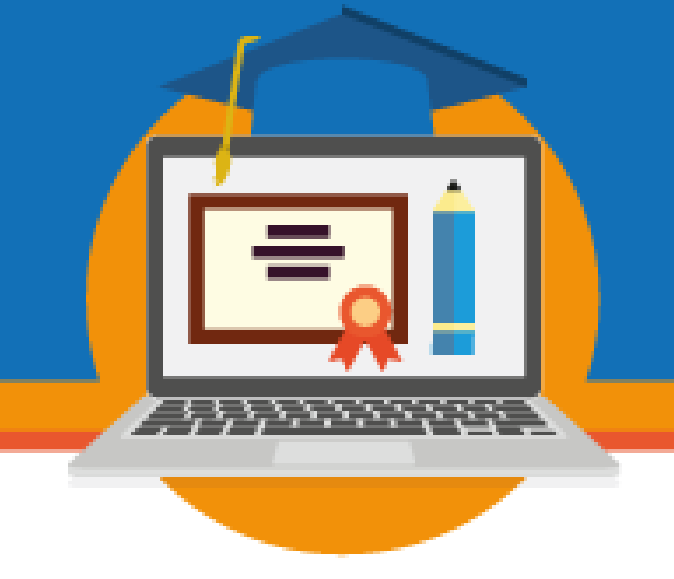

fosse realizar a perspectiva citada, pois o papel desse setor é dar suporte às ações da Secretaria como um todo.

Diante das percepções de (não) institucionalização no período de 10 anos de UAB na UFMS, a SEDFOR trabalhou no seu primeiro ano de gestão em conjunto com as unidades setoriais, para abrir esse "nicho" que se fechou, em parte, pela resistência da própria instituição em assumir a EaD como parte da UFMS.

Entretanto, essas ações da SEDFOR só são possíveis, porque há interesse institucional na $\mathrm{EaD}$, o que não foi percebido anteriormente. Além disso, as ações dos gestores da CED/PREG, mesmo ecoando sem resposta, deram base para que a SEDFOR, hoje, consolidasse parcerias, políticas, estratégias e articulações dentro e fora da instituição, com outras IPES e com municípios polos da UAB.

O processo é lento quanto ao uso de tecnologias digitais, pois a infraestrutura tecnológica e de recursos humanos é ínfima sob a demanda que se apresenta, não só para os cursos a distância, mas também para os cursos presenciais, pois há interesse da administração em usar cada vez mais, as tecnologias da EaD nos cursos presenciais e possibilitar aprendizagem e vivências acadêmicas em espaços virtuais para todos os estudantes.

O relato dessa trajetória levou à percepção de um processo lento de institucionalização, cujas ações começam a ser desencadeadas com a nova gestão institucional iniciada em dezembro de 2016, o que evidencia interesse em dar um novo patamar para a EaD da UFMS.

$\mathrm{O}$ caminho a ser percorrido é árduo e longo, mas o que move os profissionais da EaD nesse contexto é a certeza de que se trabalha por uma educação superior a distância pública, gratuita, de qualidade, com compromisso social com a educação, que forme profissionais críticos e conscientes de seu papel na sociedade como um todo. 


\section{REFERÊNCIAS BIBLIOGRÁFICAS}

BRASIL. Decreto n. 5.622, de 19 de dezembro de 2005.

BRASIL. Decreto n. 5.800, de 08 de junho de 2006.

BRASIL. Ministério da educação. Secretaria de educação a distância. Referenciais de qualidade para educação superior a distância. MEC/SEED: Brasília, 2007. Disponível em: $<$ http://portal.mec.gov.br/seed/arquivos/pdf/referenciaisead.pdf $>$. Acesso em: 01 out. 2009.

BRASIL. Ministério da Educação. Secretaria de Educação Superior. Relatório Final da Comissão Assessora para Educação a Distância. Portaria Ministerial n. 335/2002, 2002.

FREITAS, Helena Costa Lopes de. A (nova) política de formação de professores: a prioridade postergada. Educ. Soc., Campinas, vol. 28, n. 100 - Especial, p. 1203-1230, out. 2007. Disponível em: <http://www.cedes.unicamp.br>. Acesso em: 23 ago. 2009.

GATTI, B. A. (Coord.).; BARRETO, E. S. S. Professores do Brasil: impasses e desafios. Brasília: UNESCO, 2009.

GILBERTO, Irene Jeanete Lemos. A educação a distância no cenário das políticas educacionais. Educação \& Linguagem, v. 12, n. 19, Jan./ Jun. 2009. Disponível em: 


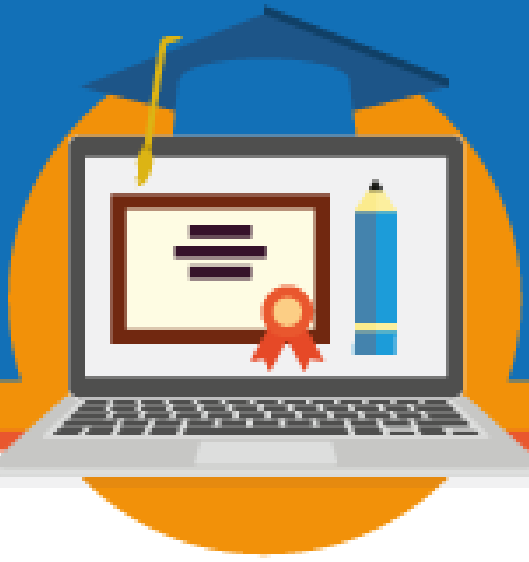

$<$ https://www.metodista.br/revistas/revistas-ims/index.php/EL/article/viewFile/812/880>. Acesso em: 23 ago. 2009. 